\title{
Facile synthesis of 9-azajulolidine and its application to post-Ullmann reactions
}

\author{
Ken-Tsung Wong, ${ }^{\mathrm{a}, *}$ Sung-Yu $\mathrm{Ku}^{\mathrm{a}}$ and Feng-Wen $\mathrm{Yen}^{\mathrm{b}}$ \\ ${ }^{a}$ Department of Chemistry, National Taiwan University, Taipei 106, Taiwan \\ ${ }^{\mathrm{b}}$ Luminescence Technology Corporation, Hsin-Chu 300, Taiwan
}

Received 25 April 2007; revised 15 May 2007; accepted 16 May 2007

Available online 18 May 2007

Dedicated to the late Professor Yoshihiko Ito

\begin{abstract}
This Letter describes the efficient synthesis of 9-azajulolidine from readily available reagents and its utilization as an effective electron-rich ligand for post-Ullmann-type reactions, that is, for $\mathrm{C}(\operatorname{aryl})$-heteroatom $(\mathrm{N}, \mathrm{O}, \mathrm{S})$ bond formation reactions, with dramatically enhanced reaction rates.
\end{abstract}

(c) 2007 Elsevier Ltd. All rights reserved.

4-(Dialkylamino)pyridine derivatives are efficient organocatalysts in various organic reactions, ${ }^{1}$ including the acylation and silylation of alcohols and amines, transesterification, amide formation, Baylis-Hillman reactions, and nucleophilic substitutions. Many attempts have been made to develop sophisticated chiral 4-(dialkylamino)pyridine derivatives for use as catalysts in asymmetric synthesis ${ }^{2}$ and for kinetic resolutions of alcohols and amines. The catalytic activity of 4-(dialkylamino)pyridine derivatives depends strongly on the electron-donating capability of the dialkylamino group; for example, 4-pyrolidinopyridine (PPY) is more reactive than 4-dimethylaminopyridine (DMAP). ${ }^{3}$ More recently, 9-azajulolidine (9-AJ) ${ }^{4}$ and a related analogue ${ }^{5}$ have been demonstrated to display remarkably enhanced catalytic activities toward the acylation of sterically hindered alcohols; in these structures, the 4-amino group is conformationally restricted through ring fusion to the pyridine ring. The enhanced activity of these compounds is ascribed mainly to the high stability of their intermediate $N$-acylpyridinium ions, ${ }^{6}$ a consequence of the relatively high electron densities on their pyridine rings, resulting from a combination of the conformational restriction of the 4-amino group and the inductive electron donating effect of the alkyl groups.

\footnotetext{
Keywords: Ullmann reaction; 9-Azajulolidine; $\mathrm{C}-\mathrm{N}$ bond formation.

* Corresponding author. Tel.: +886 23366 1665; fax: +88623366

1667; e-mail: kenwong@ntu.edu.tw
}

Although post-Ullmann reactions employing copper salts and nitrogen-containing heteroarenes (e.g., pyridine, bipyridine, terpyridine, and 1,10-phenanthroline) as co-catalysts have emerged as alternative means for the construction of $\mathrm{C}(\operatorname{aryl})-\mathrm{N}, \mathrm{C}(\operatorname{aryl})-\mathrm{O}$, and $\mathrm{C}(\operatorname{aryl})-$ $\mathrm{S}$ bonds. ${ }^{7,8}$ However, the relatively lower reactivities of these catalytic systems - when compared to, for example, the corresponding Pd-catalyzed reactions ${ }^{9}$ and other auxiliary ligands mediated Ullmann-type reactions ${ }^{10}$ must be improved substantially if they are able to find practical applications. We envisioned that the high electron density of 9-azajulolidine might make it a superior candidate for use as an auxiliary ligand in post-Ullmann reactions. Unfortunately, previous syntheses ${ }^{11}$ of 9azajulolidine starting from non-commercial 1,6naphthyridine have limited its availability and, hence, exploitation in organic synthesis. Thus, an efficient synthesis of 9-azajulolidine is thus highly desirable for its subsequent utilization in organic synthesis. In this Letter, we report the efficient synthesis of 9-azajulolidine from commercially, readily, available reagents and its subsequent utilization as a co-catalyst for $\mathrm{Cu}$-mediated $\mathrm{C}(\operatorname{aryl})$-heteroatom $(\mathrm{N}, \mathrm{O}, \mathrm{S})$ bond formation.

Scheme 1 depicts our synthesis of 9-azajulolidine. The Heck reaction of 4-amino-3,5-dibromopyridine ${ }^{12}$ (1) with an excess amount of ethyl acrylate in the presence of catalytic amounts of $\mathrm{Pd}(\mathrm{OAc})_{2}(1 \mathrm{~mol} \%)$ and $\mathrm{P}(o-$ tolyl $)_{3}(3 \mathrm{~mol} \%)$ gave bisacrylate 2 in an isolated yield of $78 \%$ after purification through recrystallization. Subsequent Pd-catalyzed hydrogenation of the olefinic 
<smiles>CCOC(=O)/C=C/c1cncc(/C=C/C(=O)OCC)c1N</smiles><smiles></smiles>

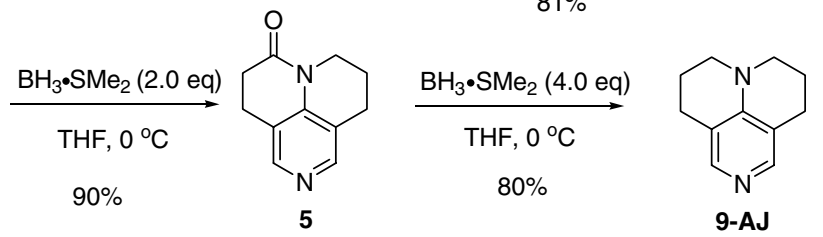

Scheme 1. Synthetic pathway toward 9-azajulolidine (9-AJ).

bonds of 2 afforded diester $3(52 \%)$ and lactam $4(46 \%)$, implying that the former converted to the latter spontaneously during the course of the reduction. The isolated diester 3 underwent intramolecular cyclization in DMF under reflux to give lactam 4 in $81 \%$ isolated yield. More conveniently, lactam $\mathbf{4}$ was isolated in $70 \%$ yield directly from the bisacrylate 2 when, after completion of the catalytic hydrogenation, the solvents were evaporated under vacuum and the residue was then heated under reflux in dry DMF. Treatment of lactam 4 with $\mathrm{BH}_{3} \cdot \mathrm{SMe}_{2}$ (2 equiv) in THF at $0{ }^{\circ} \mathrm{C}$ led to the formation of the new lactam $\mathbf{5}$ in an isolated yield of $90 \%$. The formation of $\mathbf{5}$ implies that the amide carbonyl group of $\mathbf{4}$ was reduced initially, rather than the ester group, because of its higher chelating ability toward borane; the resulting cyclic amino group subsequently reacted with the ester moiety to form lactam 5. Finally, we isolated 9 -azajulolidine in $80 \%$ yield after reacting 5 with an excess amount of $\mathrm{BH}_{3} \cdot \mathrm{SMe}_{2}$.

Next, we turned our attention to the feasibility of utilizing 9-azajulolidine as an electron-rich auxiliary ligand for $\mathrm{Cu}$-catalyzed post-Ullmann $\mathrm{C}($ aryl $)-\mathrm{N}$ bond formation for the preparation of triarylamines, which are important hole-transporting materials in many organic optoelectronic devices, such as organic light-emitting diodes and xerography devices. ${ }^{13}$ Thus, we reacted $N, N$-diphenylamine (the nitrogen source) with various aryl iodides in the presence of air-stable $\mathrm{CuI}(5 \mathrm{~mol} \%)$ as the catalyst, 9-azajulolidine $(10 \mathrm{~mol} \%)$ as the co-catalyst, and $\mathrm{NaO}^{t} \mathrm{Bu}$ (2 equiv) as the base. The reaction was dramatically facilitated, and the desired triarylamines were isolated in excellent yields (Table 1) as compared to the reaction without adding 9-AJ as a cocatalyst. This reaction is rather insensitive to the electronic characteristics of the aryl iodides (entries 1-3), but provided a slightly lower yield when the aryl iodide possessed an ortho substituent (entry 4); a doubly coupled product was also obtained in good yield (entry 5).
Table 1. Cu-catalyzed aminations of aryl iodides in the presence of 9azajulolidine

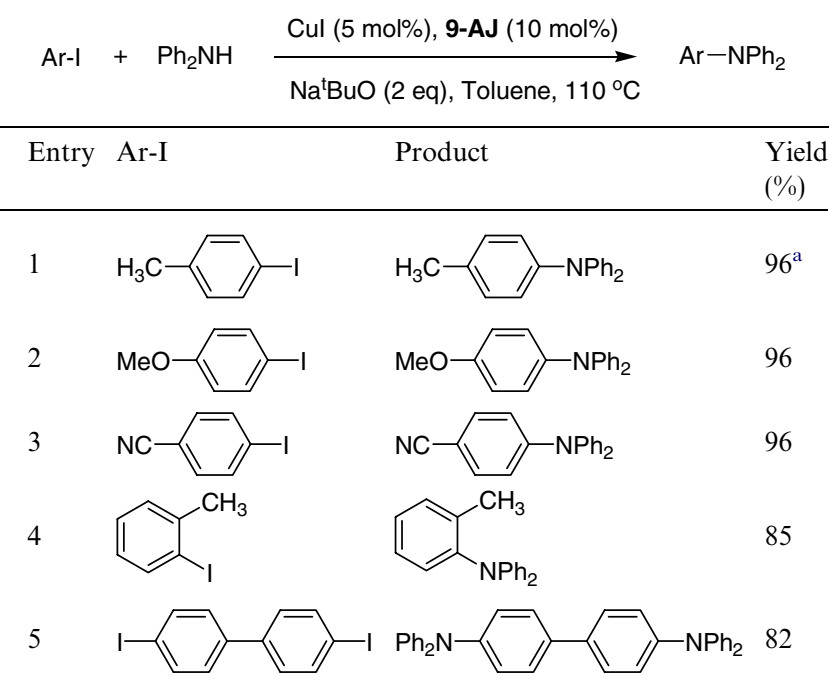

\footnotetext{
${ }^{\text {a }}$ The same product was isolated in $8 \%$ yield as the reaction was carried out without adding 9-AJ.
}

Unfortunately, aryl bromides and chlorides were inert to coupling with diarylamines under these conditions.

In addition, alkylaryl amines, primary aryl amines, carbazole, and indole were also suitable arylamine sources for coupling with 4-iodotoluene under these conditions. The isolated yields ranged from good to excellent (Table 2). Although a strong base such as $\mathrm{NaO}^{t} \mathrm{Bu}$ was necessary for use in the couplings of the less-acidic amines such as alkylaryl amines, primary and secondary arylamines, a weak base such as $\mathrm{K}_{3} \mathrm{PO}_{4}$ was sufficient for

Table 2. 9-Azajulolidine-mediated $\mathrm{N}$-arylations of various aryl amines with 4-iodotoluene

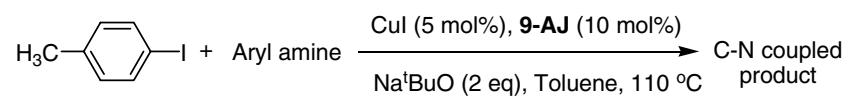

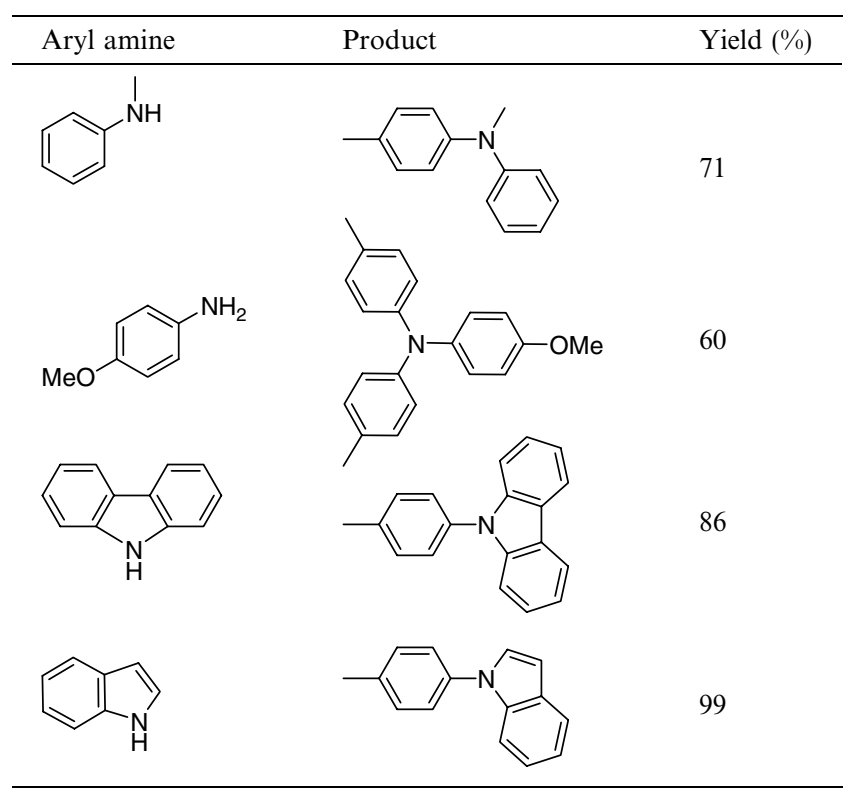




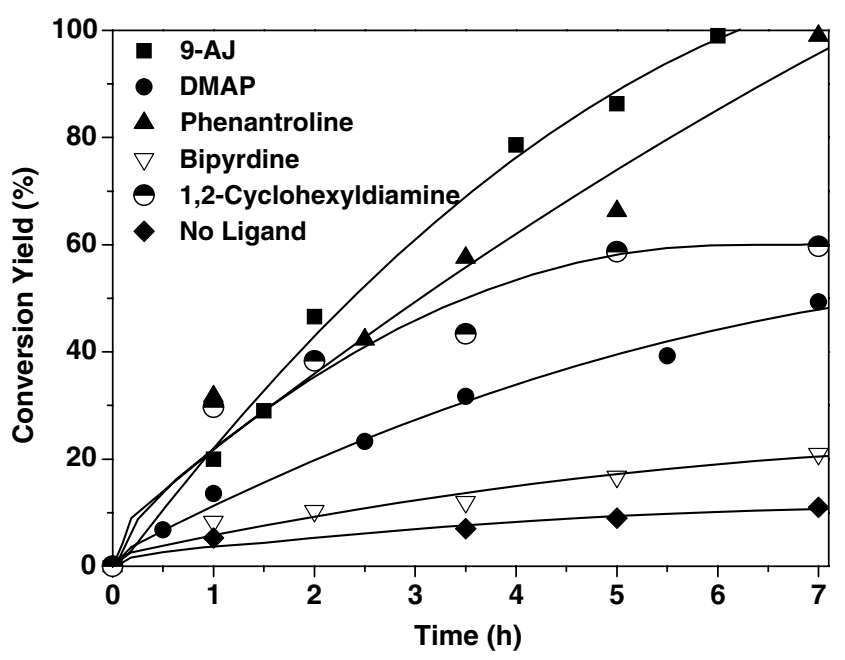

Figure 1. Conversions of 4-iodotoluene and $N, N$-diphenylamine in $\mathrm{Cu}$-catalyzed Ullmann reactions performed in the presence of various heteroarenes and trans-1,2-cyclohexyldiamine as co-catalysts.

high-yield couplings of the more-acidic amines (i.e., carbazole and indole).

Figure 1 presents a comparison of the reaction efficiency of our present system in relation to those employing other pyridine derivatives - that is, DMAP, ${ }^{14} 2,2^{\prime}$ bipyridine, ${ }^{15} 1,10$-phenanthroline, ${ }^{16}$ and trans-1,2-cyclohexyldiamine ${ }^{17}$ - as co-catalysts. In the presence of a catalytic amount of 9-azajulolidine, 4-iodotoluene reacted with diphenylamine approximately three times faster than it did under the same reaction conditions when using DMAP as the co-catalyst and six times faster than it did when using 2,2'-bipyridine. 9-Azajulolidine exhibited a comparable, but slightly higher, reactivity relative to that of 1,10 - phenanthroline.

We ascribe the evident enhancement of the reaction rate mainly to the highly electron-rich character of 9-azajulolidine, as has been suggested previously for its promotion of the esterification rate of tertiary alcohols. ${ }^{6}$ For this specifically studied case, our present catalytic method exhibited better efficiency as compared to the similar reaction using non-pyridine-based bidendate ligand such as trans-1,2-cyclohexyldiamine.

Next, we explored the feasibility of applying the current protocol for the preparation of diaryl ethers, using $\mathrm{Cs}_{2} \mathrm{CO}_{3}$ as the base for these $\mathrm{C}(\operatorname{aryl})-\mathrm{O}$ bond formation reactions (Table 3). The $\mathrm{Cu}$-catalyzed $\mathrm{C}-\mathrm{O}$ bond formation was not successful without the presence of 9-AJ , in addition, at the same co-catalyst loadings [CuI $(5 \mathrm{~mol} \%)$ and 9-AJ $(10 \mathrm{~mol} \%)]$, the isolated yields of the ethers were lower than those from the corresponding $\mathrm{C}-\mathrm{N}$ bond formation reactions. The chemical yields improved significantly, however, when we doubled the amounts of the co-catalysts. Electron-rich phenol derivatives, even those bearing an ortho substituent or two substituents, reacted with 4-iodotoluene to afford the corresponding diaryl ethers in good to excellent yields. The reaction of phenol itself, on the other hand, provided the desired product in low yield; phenol deriva-
Table 3. Cu-catalyzed O-arylations of various phenol derivatives with 4-iodotoluene in the presence of 9-azajulolidine

Isolate yield

${ }^{\text {a }}$ Only recovered the starting materials as the reaction was carried out without adding 9-AJ as a co-catalyst.

${ }^{\mathrm{b}} \mathrm{CuI}(5 \mathrm{~mol} \%)$, 9-AJ (10 mol \%).

${ }^{\mathrm{c}} \mathrm{CuI}(10 \mathrm{~mol} \%)$, 9-AJ (20 mol \%).

tives bearing electron-withdrawing substituents, such as 4-bromophenol and 4-nitrophenol, were inert under these reaction conditions.

Table 4 displays the results obtained when we applied this method to C(aryl)-S bond formation. Higher nucleophilicity of thiophenols, relative to that of phenol derivatives, was beneficial for their reactions with 4-iodotoluene, leading to a significant background reaction. Without adding 9-AJ as a co-catalyst, 4-bromothiophenol reacted with 4 -iodotoluene to afford the product in $22 \%$ yield. However, the desired diaryl thioethers were isolated in high isolated yields in the presence of 9-AJ. For example, 4-bromothiophenol reacted with 4-iodotoluene to produce the corresponding diaryl thioether in $98 \%$ yield.

Table 4. Cu-catalyzed S-arylations of various thiophenols with 4iodotoluene in the presence of 9-azajulolidine

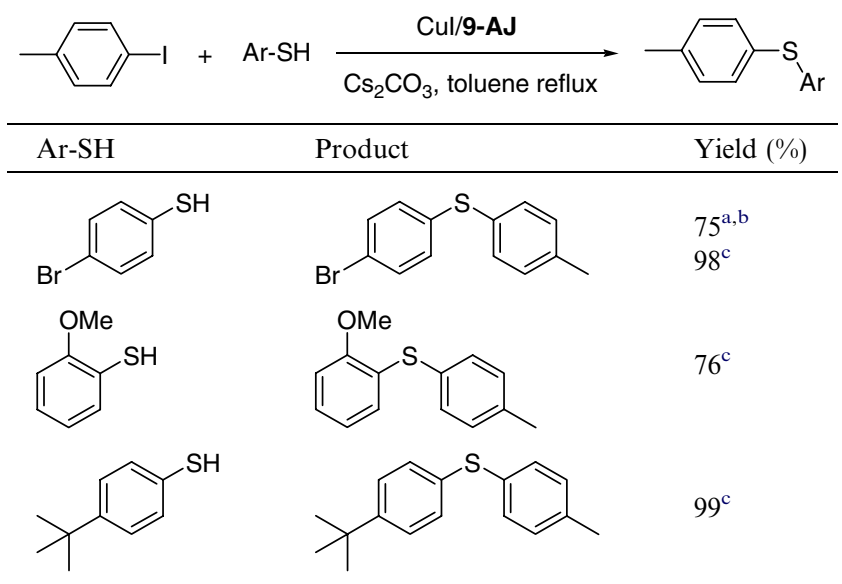

\footnotetext{
${ }^{\mathrm{a}}$ The same product was isolated of a yield of $22 \%$ as the reaction was carried out without adding $\mathbf{9 - A J}$ as a co-catalyst.

${ }^{\mathrm{b}} \mathrm{CuI}(5 \mathrm{~mol} \%)$, 9-AJ $(10 \mathrm{~mol} \%)$.

${ }^{\mathrm{c}} \mathrm{CuI}(10 \mathrm{~mol} \%)$, 9-AJ (20 mol \%).
} 
In summary, we have established a facile and efficient synthesis of 9-azajulolidine in reasonable yield from readily available reagents. Because of its highly electron-rich character, 9-azajulolidine is an effective auxiliary ligand for promoting post-Ullmann coupling reactions ${ }^{18}$ leading to the construction of $\mathrm{C}($ aryl $)-$ heteroatom $(\mathrm{N}, \mathrm{O}, \mathrm{S})$ bonds.

\section{Acknowledgment}

This study was supported by the National Science Council and Ministry of Economic Affairs (95-EC-17A-08-S1-042) of Taiwan.

\section{Supplementary data}

Detailed experimental procedures, spectroscopic characterization, and NMR spectra of new compounds are available. Supplementary data associated with this article can be found, in the online version, at doi:10.1016/ j.tetlet.2007.05.094.

\section{References and notes}

1. Selected reviews: (a) Höfle, G.; Steglich, W.; Vorbruggen, H. Angew. Chem., Int. Ed. Engl. 1978, 17, 569-583; (b) Scriven, E. F. V. Chem. Soc. Rev. 1983, 12, 129-161; (c) Ragnarsson, U.; Grehn, L. Acc. Chem. Res. 1998, 31, 494501; (d) Murugan, R.; Scriven, E. F. V. Aldrichim. Acta 2003, 36, 21-27; (e) Spivey, A. C.; Arseniyadis, S. Angew. Chem., Int. Ed. 2004, 43, 5436-5441.

2. Selected reviews: (a) Fu, G. Acc. Chem. Res. 2000, 33, 412-420; (b) France, S.; Guerin, D. J.; Miller, S. J.; Lectka, T. Chem. Rev. 2003, 103, 2985-3012; (c) Fu, G. Acc. Chem. Res. 2004, 37, 542-547; (d) Dalko, P. I.; Moisan, L. Angew. Chem., Int. Ed. 2004, 43, 5138-5175.

3. (a) Steglich, W.; Höfle, G. Tetrahedron Lett. 1970, 54, 4727-4730; (b) Hassner, A.; Krepski, L. R.; Alexanian, V. Tetrahedron 1978, 34, 2069-2076.

4. Heinrich, M. R.; Klisa, H. S.; Mayr, H.; Steglich, W.; Zipse, H. Angew. Chem., Int. Ed. 2003, 42, 4826-4828.

5. Singh, S.; Das, G.; Singh, O. V.; Han, H. Org. Lett. 2007, 9, 401-404.

6. Held, I.; Villinger, A.; Zipse, H. Synthesis 2005, 14251430.

7. Selected reviews: (a) Ley, S. V.; Thomas, A. W. Angew. Chem., Int. Ed. 2003, 42, 5400-5449; (b) Beletskaya, I. P.; Cheprakov, A. V. Coord. Chem. Rev. 2004, 248, 23372364.
8. (a) Enguehard-Gueiffier, C.; Thery, I.; Gueiffier, A.; Buchwald, S. L. Tetrahedron 2006, 62, 6042-6049; (b) Altman, R. A.; Buchwald, S. L. Org. Lett. 2006, 8, 2779-2782.

9. Selected reviews: (a) Hartwig, J. F. Angew. Chem., Int. Ed. 1998, 37, 2046-2067; (b) Yang, B. H.; Buchwald, S. L. J. Organomet. Chem. 1999, 576, 125-146; (c) Hartwig, J. F. Synlett 2006, 1283-1294; (d) Lakshman, M. K. Curr. Org. Synth. 2005, 2, 83-112; (e) Buchwald, S. L.; Mauger, C.; Mignani, G.; Scholz, U. Adv. Synth. Catal. 2006, 348, 2349.

10. (a) Kwong, F. Y.; Klapars, A.; Buchwald, S. L. Org. Lett. 2002, 4, 581-584; (b) Kwong, F. Y.; Buchwald, S. L. Org. Lett. 2003, 5, 793-796; (c) Ma, D.; Cai, Q.; Zhang, H. Org. Lett. 2003, 5, 2453-2455; (d) Antilla, J. C.; Baskin, J. M.; Barder, T. E.; Buchwald, S. L. J. Org. Chem. 2004, 69, 5578-5587; (e) Gujadhur, R. K.; Bates, C. G.; Venkataraman, D. Org. Lett. 2001, 3, 4315-4317; (f) Cristau, H.-J.; Cellier, P. P.; Hamada, S.; Spindler, J.-F.; Taillefer, M. Org. Lett., 2004, 6, 913-916.

11. (a) Tsuda, K.; Saeki, S.; Imura, S.; Okuda, S.; Sato, Y.; Mishima, H. J. Org. Chem. 1956, 21, 1481-1486; (b) Tsuda, K.; Okuda, S.; Saeki, S.; Imura, S.; Sato, Y.; Mishima, H. J. Org. Chem. 1956, 21, 598-599; (c) Sakamoto, T.; Miura, N.; Kondo, Y.; Yamanaka, H. Chem. Pharm. Bull. 1986, 34, 2018-2023.

12. Canibano, V.; Rodriguez, J. F.; Santos, M.; Sanz-Tejedor, A.; Carreno, M. C.; Gonzalez, G.; Garcia-Ruano, J. L. Synthesis 2001, 2175-2179.

13. (a) Shirota, Y. J. Mater. Chem. 2000, 10, 1-25; (b) Borsenberger, P. M.; Weiss, D. S. Organic Photoreceptors for Imaging Systems; Marcel Dekker: New York, 1993.

14. Fagan, P. J.; Hauptman, E.; Shapiro, R.; Casalnuovo, A. J. Am. Chem. Soc. 2000, 122, 5043-5051.

15. Kelkar, A. A.; Patil, N. M.; Chaudhari, R. V. Tetrahedron Lett. 2002, 43, 7143-7146.

16. (a) Goodbrand, H. B.; Hu, N.-X. J. Org. Chem. 1999, 64, 670-674; (b) Gujadhur, R. K.; Bates, C. G.; Venkataraman, D. Org. Lett. 2001, 3, 4315-4317; (c) Kiyomori, A.; Marcoux, J.-F.; Buchwald, S. L. Tetrahedran Lett. 1999, 40, 2657-2660; (d) Han, C.; Shen, R.; Su, S.; Porco, J. A., Jr. Org. Lett. 2004, 6, 27-30.

17. Klapars, A.; Antilla, J. C.; Huang, X.; Buchwald, S. L. J. Am. Chem. Soc. 2001, 123, 7727-7729.

18. General experimental procedure: $\mathrm{CuI}(9.5 \mathrm{mg}, 0.05 \mathrm{mmol}$, $5 \mathrm{~mol} \%)$, base $(2.0 \mathrm{mmol})$, aryl iodide $(1 \mathrm{mmol})$, and aryl amine $(1.2 \mathrm{mmol})$ were added to a two-neck flask equipped with a septum. The flask was evacuated and back filled with Ar. Toluene $(4 \mathrm{~mL})$, and 9-AJ $(0.1 \mathrm{M}$ in toluene, $1 \mathrm{~mL}, 0.1 \mathrm{~mol}$ ) was added via a syringe at room temperature. The reaction mixture was heated at $110^{\circ} \mathrm{C}$ for $40 \mathrm{~h}$ and then cooled to room temperature. Water $(20 \mathrm{~mL})$ was added and the mixture extracted with $\mathrm{CH}_{2} \mathrm{Cl}_{2}$ $(40 \mathrm{~mL})$. The combined organic phases were dried $\left(\mathrm{MgSO}_{4}\right)$ and the solvent evaporated in vacuo to yield the crude product, which was purified through silica gel chromatography. 